\title{
Successful treatment with intravenous recombinant tissue plasminogen activator in an acute stroke patient presenting with hemiballism
}

\author{
Jan Paweł Bembenek, MD, PhDa \\ Marta Bilik, MD, PhDa \\ Anna Członkowska, MD, PhDa,b
}

a 2nd Department of Neurology, Institute of Psychiatry and Neurology, Warsaw, Poland

b Department of Clinical and Experimental

Pharmacology, Medical University of Warsaw, Poland

Correspondence to: Jan Bembenek

E-mail: jbembenek@02.pl

\section{Summary}

A 79-year-old woman with hypertension was evaluated 3 hours and 20 minutes after the sudden onset of left-sided weakness which lasted about 15 minutes and was followed by involuntary, coarse, flinging movements of the left extremities (hemiballistic), occurring every few minutes, and facial asymmetry. Brain computed tomography revealed no abnormalities. The patient received intravenous thrombolysis with $0.9 \mathrm{mg} / \mathrm{kg}$ of alteplase 4 hours after the symptom onset. Involuntary movements and central facial nerve paresis subsided within $\mathbf{4 8}$ hours of the thrombolysis. Magnetic resonance imaging at day 5 revealed restricted diffusion within the right globus pallidus, which was a new ischemic lesion. Thrombolysis should be considered in hemiballism as a presenting symptom of acute stroke.

KEY WORDS: acute ischemic stroke, hemiballism, involuntary movements, thrombolysis

\section{Introduction}

Hemiballism ( $\mathrm{HB}$ ) is a disorder characterized by involuntary, large amplitude proximal movements (Handley et al., 2009; Dewey and Jankovic, 1989). It typically involves the arm and leg on one side and can be associated with facial involvement on the same side (Ghika-Schmid et al., 1997; Chung et al., 2004). HB occurs in $0.1 \%$ of all acute strokes (Ghika-Schmid et al., 1997).
Thrombolytic treatment is recommended in all patients with acute ischemic stroke who fulfill the criteria for this treatment within 4.5 hours of stroke onset (Lansberg et al., 2012).

\section{Case description}

A 79-year-old woman with hypertension was evaluated 3 hours and 20 minutes after the sudden onset of left-sided weakness lasting about 15 minutes, followed by involuntary, coarse, flinging movements of the left extremities, occurring every few minutes. She had no history of trauma.

The neurological examination revealed only frequent, irregular, large amplitude movements of the proximal parts of the left extremities, dyskinetic movements of the left lower part of the face and central facial nerve paresis on the left side. The National Institutes of Health Stroke Scale (NIHSS) score was 1 - facial nerve paresis. HB is not included in the NIHSS. The patient's glucose level was $138.75 \mathrm{mg} / \mathrm{dl}$, and we therefore excluded nonketotic hyperglycemia as a reason for the involuntary movements. Brain computed tomography at admission revealed no abnormalities.

There were no contraindications for thrombolytic treatment. The patient received intravenous thrombolysis with $0.9 \mathrm{mg} / \mathrm{kg}$ of alteplase 4 hours after the symptom onset.

The involuntary movements and left-sided central facial nerve paresis subsided within 48 hours of the thrombolytic treatment.

Only diabetes was diagnosed during hospital stay. Magnetic resonance imaging (MRI) at day 5 revealed only restricted diffusion within the right globus pallidus (Fig. 1) - a new ischemic lesion - and no abnormalities on T1 or T2 images.

\section{Discussion}

The patient had classical vascular risk factors and a sudden disease onset. She experienced short-lasting left-sided weakness preceding the onset of $\mathrm{HB}$. Although thrombolytic therapy is frequently withheld in patients with symptoms that cannot be adequately measured by the NIHSS, we decided to treat the patient with alteplase, as even a score of zero on the 


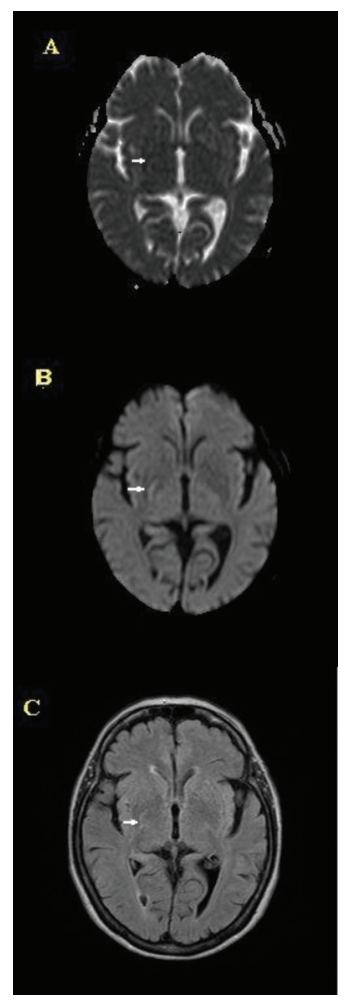

Figure $1-\mathrm{MRI}$ in an acute stroke patient presenting with hemiballism.

A - apparent diffusion coefficient map - restricted diffusion within the right globus pallidus; $\mathrm{B}$ - diffusion-weighted coefficient - hyperintense signal in right globus pallidus; C - fluid-attenuated inversion recovery (FLAIR) demonstrating hyperintense signal in right globus pallidus.

NIHSS does not exclude stroke (Martin-Schild et al., 2011). MRI confirmed a new vascular lesion in the globus pallidus. It is highly likely that this was responsible for the clinical symptoms (Mehanna and Jankovic, 2011).

According to our best knowledge, the patient here described is the third case of involuntary movements as almost the only presenting symptom of acute ischemic stroke treated with intravenous thrombolysis reported worldwide (McCollum et al., 2013; ZidvercTrajković et al., 2011).

In our patient, the HB subsided within 48 hours. We believe that thrombolytic treatment precluded extension of the ischemic lesion and allowed the HB to subside within a shorter time than the usual 3-15 days (Ristic et al., 2002).

Our case report suggests that thrombolysis should be considered in HB even when it occurs as almost the only presenting symptom of acute ischemic stroke.

\section{References}

Chung SJ, Im JH, Lee MC, et al (2004). Hemichorea after stroke: clinical-radiological correlation. J Neurol 251:725-729.

Dewey RB Jr, Jankovic J (1989). Hemiballism-hemichorea. Clinical and pharmacologic findings in 21 patients. Arch Neurol 46:862-867.

Ghika-Schmid F, Ghika J, Regli F, et al (1997). Hyperkinetic movement disorders during and after acute stroke: the Lausanne Stroke Registry. J Neurol Sci 146:109-116.

Handley A, Medcalf P, Hellier K, et al (2009). Movement disorders after stroke. Age Ageing 38:260-266

Lansberg MG, O'Donnell MJ, Khatri P, et al (2012). Antithrombotic and thrombolytic therapy for ischemic stroke: Antithrombotic Therapy and Prevention of Thrombosis, 9th ed: American College of Chest Physicians Evidence-Based Clinical Practice Guidelines. Chest $141(2$ Suppl):e601S-636S.

Martin-Schild S, Albright KC, Tanksley J, et al (2011). Zero on the NIHSS does not equal the absence of stroke. Ann Emerg Med 57:42-45.

McCollum D, Silvers S, Dawson SB, et al (2013). Resolution of acute onset hemichorea-hemiballismus after treatment with intravenous tissue plasminogen activator. Neurohospitalist 3:131-134.

Mehanna R, Jankovic J (2013). Movement disorders in cerebrovascular disease. Lancet Neurol 12:597-608. Erratum in: Lancet Neurol 2013;12:733

Ristic A, Marinkovic J, Dragasevic N, et al (2002). Long-term prognosis of vascular hemiballismus. Stroke 33:21092111.

Zidverc-Trajković J, Jovanović DR, Marjanović I, et al (2011). Successful intravenous thrombolysis in a stroke patient with hemiballism. Neurologist 17:205-207. 